\title{
High- and low-Am RE inclusion phases in a U-Np-Pu-Am-Zr alloy
}

Dawn E. Janney*, James W. Madden, Thomas P. O’Holleran

Idaho National Laboratory, Idaho Falls, ID 83415

*To whom correspondence should be addressed. Phone 208-533-7478, fax: 208-533-7863, dawn.janney@inl.gov

\section{Abstract}

Structural, microstructural, and microchemical data were collected from rare-earth inclusions in an as-cast $\mathrm{U}-\mathrm{Pu}-\mathrm{Zr}$ alloy with $\sim 3$ at $\% \mathrm{Am}, 2 \% \mathrm{~Np}$, and 9\% rare-earth elements (La, Ce, Pr, and Nd). Two RE phases with different concentrations of Am were identified.

The composition of high-Am RE inclusions is 2-5 at\% La, 15-20\% Ce, 5-10\% Pr, 25$45 \% \mathrm{Nd}, 1 \% \mathrm{~Np}, 5-10 \% \mathrm{Pu}$, and 10-20\% Am. Some areas also have O, although this does not appear to be an essential part of the high-Am RE phase. The inclusions have a face-centered cubic structure with a lattice parameter $a \sim 0.54 \mathrm{~nm}$.

The composition of the only low-Am RE inclusion studied in detail is 35-40 at\% O, 40-45 \% Nd, 1-2\% Zr, 4-5\% La, 9-10\% Ce, and 6-7\% Pr. This inclusion is an oxide with a crystal structure similar to the room-temperature structure of $\mathrm{Nd}_{2} \mathrm{O}_{3}$. Microstructural features suggest that oxidation occurred during casting, and that early crystallization of high-temperature oxides led to formation of two distinct RE phases.

\section{Introduction}

The Fuel Cycle Research and Development (FCRD) and METAPHIX projects are currently investigating ways to reduce the long-term hazards associated with minor actinides (MAs: $\mathrm{Np}, \mathrm{Am}$, and $\mathrm{Cm}$ ) in nuclear waste by incorporating them into transmutation fuels based on $\mathrm{U}-\mathrm{Pu}-\mathrm{Zr}$ alloys. In principle, the transmutation fuels can be electrochemically reprocessed,

\section{Page 2 of 25}


producing recycled fuels that contain low concentrations of rare-earth (RE) fission products (e.g., [1-11]).

To understand how U-Pu-Zr transmutation fuels change during irradiation, it is important to compare phases and microstructures in as-cast and irradiated fuels. Because Am is easily lost during high-temperature processing (e.g., $[12,13])$, it is particularly important to correctly identify Am-bearing phases. Understanding rare-earth phases is also important because these elements can migrate to the surface of fuel pins during irradiation and interact with cladding to cause fuel failures [14-16].

Previous investigations of U-Pu-Zr alloys with REs and MAs [15, 17-20] suggest that these alloys crystallize from two immiscible liquids, one forming the matrix and one forming the $\mathrm{RE}$ inclusions. The matrix consists primarily of $\mathrm{U}, \mathrm{Pu}$, and $\mathrm{Zr}$, but also contains $\mathrm{Np}$ and a low concentration of Am. The RE inclusions contain all of the REs and much of the Am, as well as some of the $\mathrm{Pu}$.

This paper provides what we believe to be the first detailed structural, microchemical, and microstructural data on RE inclusions in any actinide-RE alloy that includes Am. The data are from a $\mathrm{U}-\mathrm{Pu}-\mathrm{Zr}$ alloy with concentrations of MAs comparable to those in fuels from the FCRD and METAPHIX projects and concentrations of REs similar to those in transmutation fuel that has been irradiated to high burnup levels and reprocessed (e.g., [2-5, 20]).

\section{Samples}

$\mathrm{U}, \mathrm{Pu}, \mathrm{Pu}-\mathrm{Am}$ alloy with $18 \mathrm{wt} \% \mathrm{Am}, \mathrm{Np}, \mathrm{Zr}$, and a rare-earth alloy with 6 wt\% La, $16 \% \mathrm{Pr}, 25 \% \mathrm{Ce}$, and $53 \% \mathrm{Nd}$ were arc-melted together in an argon-atmosphere glovebox to produce approximately 10 grams of an alloy whose nominal composition is $52 \mathrm{U}-20 \mathrm{Pu}-3 \mathrm{Am}-$ 2Np-8.0RE-15Zr (where all concentrations are in weight $\%$ and RE is the rare-earth alloy). The alloy was homogenized by arc-melting it twice, inverting it between melting cycles. It was then 
arc-melted a fourth time and cast in a 4-mm (inner diameter) silica glass tube to which a zirconia mold wash had been applied, producing a cast cylinder approximately $4 \mathrm{~cm}$ long. The cylinder was allowed to cool rapidly to ambient temperature. Chemical analyses showed that the nominal and actual concentrations of all elements in the stated bulk composition matched to within plausible analytical errors [19].

A transverse slice of the cast cylinder was prepared for scanning electron microscope (SEM) analysis by cutting it in an argon-atmosphere glovebox, embedding it in acrylic resin, and grinding and polishing it by hand down to a 1200-grit finish using silicon-carbide papers with a water lubricant in an air-atmosphere glovebox. The sample was not etched or electro-polished. A thin layer of sputtered metal was applied to the sample to assist in contamination control and decrease electrostatic charging during microscopy.

\section{Analysis methods}

SEM analysis used a JEOL JSM 7000F field-emission scanning electron microscope operating at a nominal accelerating voltage of $20 \mathrm{kV}$. The microscope was equipped with an Oxford Instruments INCA X-site energy-dispersive X-ray (EDX) detector and Microspec WDX 600 wavelength-dispersive X-ray (WDX) spectrometer, both controlled by Oxford Instruments INCA software. EDX spectra were used for qualitative analysis, but could not be quantified because of software limitations in analysis of Am. The EDX detector was also used to collect Xray maps showing spatial distributions of $\mathrm{O}, \mathrm{Si}, \mathrm{Zr}$, and REs. Actinide maps were collected using the WDX detector.

Based on the results of the SEM analysis, a Ga ion beam in a FEI Quanta 3D Dual Beam FEG Focused Ion Beam (FIB) instrument was used to prepare three TEM samples, each approximately 10 micrometers square and 100 nanometers thick. High-contrast secondaryelectron (SE) images were collected during thinning. The TEM samples were removed from the 
FIB and loaded into the TEM as rapidly as possible, but were exposed to the atmosphere for a few minutes during the transfer.

TEM analyses used a JEOL 2010 transmission electron microscope with a lanthanum hexaboride $\left(\mathrm{LaB}_{6}\right)$ filament, operating at a nominal voltage of $200 \mathrm{kV}$. Images and diffraction patterns were collected with Gatan Digital Micrograph software. To aid in phase identification, numerous diffraction patterns were collected from selected areas by tilting the sample through the widest range of angles allowed by the double-tilt sample holder $\left( \pm 30^{\circ}, \pm 20^{\circ}\right)$. Distances between reflections in diffraction patterns were converted to interplanar spacings using a calibration constant determined from a commercially obtained sample of nanocrystalline gold. Phases were identified by comparing experimental TEM-EDX and diffraction data to entries in the International Centre for Diffraction Data's PDF4+ 2012 database and relevant binary phase diagrams.

TEM-EDX spectra were collected with a Bruker 133 silicon-drift detector, and elemental proportions were quantified using Bruker Quantax 200 Esprit 1.9 software. Large peaks from $\mathrm{Cu}$ and $\mathrm{Cr}$ and small peaks from $\mathrm{C}, \mathrm{Fe}, \mathrm{Co}$, and $\mathrm{Ga}$ were commonly observed, and were assumed to represent instrumental or sample-preparation artifacts.

\section{Results}

\subsection{SEM images and X-ray maps}

SEM images show a light-contrast matrix surrounding darker inclusions, which can be divided into four groups (Figure 1): high-Zr, high-Si, high-Am RE, and low-Am RE. The vast majority of inclusions that appear black in SEM images are high-Zr inclusions; high-Si inclusions also appear black but are small ( 1 $\mu \mathrm{m}$ across) and much less common than high- $\mathrm{Zr}$ inclusions. Both high-Am and low-Am RE inclusions appear lighter than high-Zr and high-Si inclusions, and high-Am RE inclusions appear lighter than low-Am RE inclusions. 
X-ray maps (Figure 2) show clear differences in composition between the two kinds of RE inclusion. Within each map, lighter-contrast areas indicate higher concentrations of the specified element; however, because contrast and brightness were adjusted individually for each map, areas with similar contrast in different maps may not have similar concentrations. High-Am $\mathrm{RE}$ inclusions have higher concentrations of $\mathrm{Am}, \mathrm{Pu}$, and $\mathrm{Ce}$ than low-Am RE inclusions, although concentrations of Pu are lower than those in the matrix. In contrast, low-Am RE inclusions have higher concentrations of $\mathrm{Nd}$ and $\mathrm{O}$ than other areas of the sample.

Concentrations of $\mathrm{La}$ and $\mathrm{Pr}$ are similar in both kinds of RE inclusion. Neither kind of RE inclusion contains $\mathrm{U}$, Np, or Zr.

Qualitative examination suggests that high-Am RE material makes up a larger fraction of the sample than low-Am RE material. Some inclusions appear to consist entirely of low-Am RE material; however, low-Am RE material also commonly forms sub-inclusions in high-Am RE inclusions. Low-Am inclusions are commonly rounded, while many high-Am inclusions are irregularly shaped or amoeboid. Low-Am inclusions commonly occur along prior grain boundaries.

\subsection{TEM and FIB data}

\subsubsection{High-Am RE inclusions}

TEM images of high-Am RE inclusions show variations in contrast within each inclusion

(Figure 3). In some images (e.g., Figures 3a and 3d), darker and lighter areas appear polygonal or planar; in others (e.g., Figure 3f), the areas appear more irregularly shaped. Higher-magnification images (e.g., Figures 3b, 3d) suggest that variations in contrast are related to differences in crystal orientation or defect density.

TEM-EDX data from high-Am RE inclusions show a composition with 2-5 at\% La, 15$20 \%$ Ce, 5-10\% Pr, $25-45 \%$ Nd, $1 \%$ Np, 5-10\% Pu, and 10-20\% Am (Table 1). Concentrations 
of $\mathrm{U}, \mathrm{Pu}$, and $\mathrm{Zr}$ vary but tend to be higher in spectra from small inclusions, suggesting that these spectra may include X-rays from adjacent high-Zr inclusions or U-Pu-Zr matrix phases. Elevated concentrations of $\mathrm{O}$ in spectra $1 \mathrm{C} 3-1,1 \mathrm{C} 3-2$, and 1C3-3 are consistent with data from nearby areas of the matrix [19], suggesting that the high oxygen concentrations may be related to local sample characteristics rather than to properties of individual phases.

Diffraction patterns from ten symmetrically non-equivalent zone axes were collected from high-Am inclusions. All of the patterns can be indexed using a face-centered cubic unit cell with a lattice parameter of $\sim 0.54 \mathrm{~nm}$. Most of the patterns show tangentially smeared reflections, some of which split near the outer edges of the patterns (Figure 4). Many of the patterns contain reflections from more than one crystal, despite being collected with the smallest available selected-area aperture (effective diameter $\sim 160 \mathrm{~nm}$ ). These characteristics indicate that the material in the inclusions is strained, and that some dislocations are organized to form sub-grain boundaries.

\subsubsection{Low-Am RE inclusion}

The TEM samples included only one low-Am RE inclusion, which is partially surrounded by high-Am material. This inclusion consists of two rounded lobes separated by a triangular region that appears darker than the surrounding material in the FIB image of this area (Figure 5a) and lighter in a low-magnification TEM image (Figure 5b).

TEM images of the material in the rounded lobes (Figures $5 \mathrm{c}$ and $5 \mathrm{~d}$ ) show numerous dislocations and pairs of adjacent dark and light sub-inclusions. Despite variations in the sizes of the sub-inclusions, the diameters of most of the dark inclusions in these figures are slightly less than two and a half times the diameters of the corresponding light inclusions. (Exceptions may indicate that one of the inclusions was truncated by the plane of the sample, and therefore the diameter of the inclusion as it appears in the image is smaller than its true diameter.) 
Quantitative analysis of the compositions of the dark and light sub-inclusions is impossible because spectra from these materials include X-rays from over- or under-lying material outside the sub-inclusions. Spectra from dark sub-inclusions show significantly higher concentrations of $\mathrm{Zr}$ and actinides (primarily $\mathrm{U}$ and $\mathrm{Pu}$ ) than those from other areas of the lowAm RE inclusion.

Spectra from the light sub-inclusions resemble those from nearby materials outside the sub-inclusions. Although the identification is not conclusive, the data are consistent with identification of the light sub-inclusions as gas bubbles, possibly filled with $\mathrm{O}$.

EDX spectra from material outside the sub-inclusions consistently show $\sim 35-40$ at $\%$ O, 1-2\% Zr, 4-5\% La, 9-10\% Ce, 6-7\% Pr, and 40-45\% Nd (Table 2). None of these spectra has a significant concentration of any actinide.

Images of the material in the triangular region show numerous small holes that appear to have formed when a thin piece of material broke out of the TEM sample (Figure 5c). The highest concentrations of $\mathrm{O}$ occur in measurements from this area (spectra $2 \mathrm{~A} 1-1,2,8,9$, and 11). However, these higher concentrations may indicate reduced absorption of O X-rays because of the smaller sample thickness rather than differences in the composition of the material.

Diffraction patterns from ten symmetrically non-equivalent zone axes were collected from low-Am RE inclusions. All of the patterns show circular reflections (e.g., Figure 6). Some patterns show strong diffuse scattering. All of the patterns could have been produced by $\mathrm{Nd}_{2} \mathrm{O}_{3}$ with a primitive trigonal space group such as P-3m1 or P321 (PDF4+ cards 04-007-5405 and 04015-5004 respectively) but not by $\mathrm{Nd}, \mathrm{NdO}_{2}$, cubic $\mathrm{Nd}_{2} \mathrm{O}_{3}, \mathrm{Nd}_{6} \mathrm{O}_{11}$, or $\mathrm{Nd}_{6} \mathrm{UO}_{12}$ (cards 04-0010503, 04-007-0500, 04-002-4368, 00-045-0087, and 00-019-0830 respectively). 


\section{Discussion}

This research presents structural, microstructural, and microchemical information about phases in two kinds of rare-earth inclusions in an alloy with nominal composition 52U-20Pu3Am-2Np-8.0RE-15Zr (where RE is a rare-earth alloy of $6 \mathrm{wt} \% \mathrm{La}, 16 \% \mathrm{Pr}, 25 \% \mathrm{Ce}$, and $53 \%$ Nd). Both phases have similar concentrations of $\mathrm{La}$ and $\mathrm{Pr}$, but one has higher concentrations of $\mathrm{Ce}, \mathrm{Pu}$, and $\mathrm{Am}$, and the other has higher concentrations of $\mathrm{Nd}$ and $\mathrm{O}$. Despite some individual EDX spectra that probably include X-rays from adjacent materials or sub-inclusions, neither rare-earth phase has a significant concentration of $\mathrm{U}, \mathrm{Np}$, or $\mathrm{Zr}$.

\subsection{High-Am inclusions}

SEM X-ray maps, TEM-EDX spectra, and electron-diffraction data from high-Am RE inclusions lead to conflicting ideas about whether these inclusions are metals or oxides. The Xray maps (Figure 2) show oxygen in both of the rare-earth phases and the matrix (although with varying concentrations in different phases), suggesting that the high-Am RE inclusions have a significant concentration of $\mathrm{O}$. However, these maps are likely to include $\mathrm{O}$ from surface phases formed with reactions with the water or the atmosphere during sample preparation and handling, and therefore should not be interpreted as accurate representations of concentrations of $\mathrm{O}$ in the as-cast alloy.

Although it is likely that some oxidation of the TEM sample occurred while it was being transferred between the FIB and TEM, the common occurrence of TEM-EDX spectra with low concentrations of $\mathrm{O}$ suggests that $\mathrm{O}$ is part of the alloy in areas where it is reported in relatively high concentrations. Accurate quantification of O in TEM-EDX spectra is notoriously difficult, but the concentrations of O shown by most of the TEM-EDX spectra from the high-Am RE inclusions seem too low for an oxide. 
In contrast, the lattice parameter determined from the diffraction data $(a \sim 0.54 \mathrm{~nm})$ is consistent with face-centered cubic oxides such as $\mathrm{Ce}_{0.5} \mathrm{Nd}_{0.5} \mathrm{O}_{1.75}$ and $\mathrm{U}_{0.651} \mathrm{Nd}_{0.349} \mathrm{O}_{2.260}(\mathrm{PDF} 4+$ cards 04-012-6397 and 04-008-3280, both with $a$ between 0.54 and $0.55 \mathrm{~nm}$ ). However, this lattice parameter is too large for a face-centered cubic RE, actinide, or RE-actinide alloy (e.g., $a$ $\sim 0.516 \mathrm{~nm}$ for $\mathrm{Ce}_{0.7} \mathrm{Nd}_{0.3}, 0.50 \mathrm{~nm}$ for $\mathrm{Ce}_{0.7} \mathrm{Pu}_{0.3}, 0.49 \mathrm{~nm}$ for $\beta \mathrm{Am}$, and $0.464 \mathrm{~nm}$ for $\delta \mathrm{Pu}$; PDF4+ cards 04-001-0493, 04-004-2517, 04-003-3175, and 04-003-3176, respectively).

To reconcile the TEM-EDX and diffraction data, it is useful to consider the relevant phase diagrams. To our knowledge, there are no published phase diagrams with three or more elements in the La-Ce-Pr-Nd-Zr-Pu-Am-O system. Considering only compositions with proportions of REs and actinides similar to those in the high-Am RE inclusions, the Ce-La, NdPr, La-Nd, Ce-Nd, Ce-Pr, La-Pr, Ce-Pu, and Nd-Pu binary phase diagrams all show a solid solution with a body-centered cubic structure at the solidus [21-28]. The Nd-Pu, Nd-Pr, La-Nd, Ce-Nd, and La-Pr phase diagrams show a second phase transition from body-centered cubic to hexagonal close-packed structures at lower temperatures. In contrast, $\mathrm{Ce}-\mathrm{La}, \mathrm{Ce}-\mathrm{Pr}$, and $\mathrm{Ce}-\mathrm{Pu}$ phase diagrams a second phase transition from the original body-centered cubic to face-centered cubic, with a third transition from face-centered cubic to hexagonal close-packed structures in the Ce-La and Ce-Pr phase diagrams.

The binary phase diagrams suggest that the high-Am RE material first crystallized as a complex solid solution with a body-centered cubic structure, probably at a temperature between $\sim 1000$ and $1200{ }^{\circ} \mathrm{C}$. Details of the transformation between this original structure and the currently observed highly strained face-centered cubic structure are unknown, but are likely to involve diffusion-related processes leading to formation of small domains with different compositions or structures and corresponding distortion of crystal lattices. Given the similarity in 
crystal structures and lattice parameters of the high-Am RE phase and a number of RE and REactinide oxides, it seems likely that the oxygen shown in the TEM-EDX spectra occurs in small oxide domains within the high-Am RE inclusions.

In conclusion, it seems reasonable to identify the material in the high-Am RE inclusions as a complex, spatially heterogeneous $\mathrm{Pu}-\mathrm{Am}-\mathrm{RE}$ alloy that may contain small areas of oxides. The anomalously large lattice parameter, smeared reflections, and internal contrast variations in the high-Am RE inclusions can all be explained as consequences of local variations in crystal structure or orientation that formed as a result of phase transitions "frozen" in intermediate states by the rapid cooling of the sample.

\subsection{Low-Am inclusions}

The SEM, TEM-EDX, and electron diffraction data are all consistent with the identification of the low-Am RE phase as an oxide similar to trigonal $\mathrm{Nd}_{2} \mathrm{O}_{3}$. This identification is unexpected, as concentrations of $\mathrm{O}$ should have been far too low to allow formation of oxides except on exposed surfaces. Although the original source of the $\mathrm{O}$ is unknown, it is possible to determine when the oxidation occurred and what this implies about the RE inclusions.

$\mathrm{Nd}$ oxidizes readily in contact with the atmosphere, and the oxide spalls away from the underlying metal [29]. SEM images (e.g., Figure 1a) show surface pits that may be from oxidation-related spalling of RE inclusions, and TEM images of the low-Am inclusion show numerous small, sharp-edged holes that would not have survived milling in the FIB (Figures 5b, 5c). However, the pits in the SEM sample occur in high-Am RE inclusions. Locations of holes in the TEM sample correspond to unusually dark areas in the FIB image, suggesting that another phase was present in these areas. There is no evidence for preferential spalling of the low-Am RE inclusions or sample breakage where low-Am materials are adjacent to high-Am materials or 
the matrix. If oxidation occurred at relatively low temperatures, it is also difficult to explain why the two kinds of RE inclusions occur in relatively large domains rather than the small-scale intergrowths that would be expected if the separation occurred as a result of diffusion. Thus, the microstructural evidence suggests that low-Am RE materials oxidized before SEM and TEM sample preparation.

Although REs oxidize readily, it seems unlikely that the low-Am RE inclusions first formed as $\mathrm{Nd}_{2} \mathrm{O}_{3}$ in the $\mathrm{RE}$ feedstock because of the high melting temperatures of $\mathrm{RE}$ oxides (e.g., $2272{ }^{\circ} \mathrm{C}$ for $\mathrm{Nd} 2 \mathrm{O} 3$ [30]). Despite poorly constrained temperatures during arc-melting, it seems unlikely that any $\mathrm{Nd}_{2} \mathrm{O}_{3}$ that might originally have been in the RE feedstock would have melted completely before casting, and equally unlikely that a solid oxide would have reacted with multiple feedstock materials to the extent required to produce the observed compositions of the low-Am RE inclusions. The paired sub-inclusions in the low-Am RE inclusions are likewise difficult to explain as consequences of oxidation in the feedstock.

The observed microstructures are consistent with oxidation of the low-Am RE material during casting. The consistently close spacing of the dark and light sub-inclusions in each pair suggests that the low-Am inclusion had already oxidized by the time these sub-inclusions formed. Formation of the observed dislocations and paired sub-inclusions would have required movement of individual atoms, which is likely to occur more rapidly at higher temperatures (i.e., during casting rather than room-temperature sample storage or handling).

Oxidation during casting is also consistent with the observed formation of two different RE phases occurring in relatively large domains. $\mathrm{Nd}_{2} \mathrm{O}_{3}$ and $\mathrm{Ce}_{2} \mathrm{O}_{3}$ crystallize with the same structure and similar lattice parameters at $\sim 1800{ }^{\circ} \mathrm{C}[30,31]$ and retain this structure during cooling to room temperature. In contrast, RE and actinide metals crystallize at temperatures

\section{Page 12 of 25}


below $1200{ }^{\circ} \mathrm{C}$ [32]. Thus, the observed spatial relationships between the two kinds of RE would be a likely consequence of a two-stage crystallization process in which the low-Am RE inclusions crystallized as oxides at high temperatures, consuming most of the available $\mathrm{O}$, and the remaining liquid crystallized at lower temperatures to form the high-Am RE inclusions. In this scenario, smaller-scale microstructures (segregation of the dark and light sub-inclusions in the low-Am material and formation of domains and sub-grains in the high-Am RE material) would have formed separately in each kind of material at lower temperatures.

\section{Conclusions}

Previous studies have shown that REs form discrete inclusions in U-Pu-Zr-RE-Am alloys, and that these inclusions also contain $\mathrm{Am}$ and Pu. However, these inclusions have not been studied in detail. The present study uses scanning and transmission electron microscopy to characterize compositions, crystal structures, and microstructures of RE inclusions in an alloy whose nominal composition is $52 \mathrm{U}-20 \mathrm{Pu}-3 \mathrm{Am}-2 \mathrm{~Np}-8.0 \mathrm{RE}-15 \mathrm{Zr}$ (where RE is a rare-earth alloy consisting of $6 \% \mathrm{La}, 16 \% \mathrm{Pr}, 25 \% \mathrm{Ce}$, and $53 \% \mathrm{Nd}$ and all proportions are by weight). This alloy contains two kinds of RE inclusion, which have different compositions and crystal structures, and can be distinguished by contrast differences in SEM images.

The more common of the two RE inclusion phases contains $~ 10-20$ at\% Am, and is therefore an important phase to understand when designing strategies for casting and reprocessing Am-bearing metal fuels. Although the melting temperature of this phase is unknown, binary RE phase diagrams suggest that it is between $\sim 1000$ and $1200{ }^{\circ} \mathrm{C}$. This phase has a face-centered cubic structure, with a lattice parameter that is unusually large for an alloy. TEM data indicates that the lattice is highly strained, and that the inclusions have numerous small domains and sub-grains. These domains and sub-grains probably formed as a result of rapid cooling of a complex alloy, and are not equilibrium features. 
The less common RE inclusion phase commonly occurs as sub-inclusions in high-Am RE inclusions. It is an oxide, with a structure similar to that of trigonal $\mathrm{Nd}_{2} \mathrm{O}_{3}$ and a composition of -35-40 at\% O, 40-45 \% Nd, 1-2\% Zr, 4-5\% La, 9-10\% Ce, 6-7\% Pr. It does not contain a significant concentration of any actinide. Although the source of the oxygen is still being investigated, it seems likely that oxidation occurred during alloy preparation or casting, possibly at temperatures above $2000{ }^{\circ} \mathrm{C}$.

As a consequence of these formation mechanisms, the relative proportions of high- and low-Am inclusions should reflect the concentration of oxygen available during casting and cooling. If no oxygen were present, it seems likely that there would be only one RE phase, which would have a structure similar to that of the high-Am RE phase in the present sample.

Mass-balance considerations suggest that the concentration of $\mathrm{Nd}$ in this single RE phase would be higher than that in the high-Am RE inclusions in the present sample, and that concentrations of Am and Ce would be lower.

Because the present data are from a rapidly cooled sample examined in as-cast condition, microstructural differences between these samples and more slowly cooled or annealed samples should be expected. In view of the wide temperature range over which the trigonal $\mathrm{Nd}_{2} \mathrm{O}_{3}$ structure is stable, it seems likely that the crystal structure of the low-Am RE inclusions would not change if the samples had been cooled more slowly or annealed. Despite the disequilibrium microstructures (and perhaps phases) in the high-Am inclusions, significant diffusion between the high-Am RE inclusions and adjacent matrix seems unlikely, and compositions of individual RE inclusions in the current sample are likely to be similar to those in slowly cooled or annealed samples. 


\section{Acknowledgments}

We would like to thank the many people in the Nuclear Operations, Safeguards and Security, Radiological Safety, and Nuclear Science \& Technology organizations at Idaho National Laboratory (INL) who made it possible to carry this work out safely. FIB operations and electron microscopy were carried out in the Electron Microscopy Laboratory, Materials and Fuels Complex (MFC), INL. We also thank Drs. J. Rory Kennedy, Robert D. Mariani, and Jeffrey J. Giglio for helpful discussions, and Dr. Brandon D. Miller for loading the TEM samples.

The research presented here was supported by the U.S. Department of Energy, Office of Nuclear Energy, under DOE Idaho Operations Office Contract DE-AC07-05ID14517. 


\section{References}

[1] W.J. Carmack, D.L. Porter, Y.I. Chang, S.L. Hayes, M.K. Meyer, D.E. Burkes, C.B. Lee, T. Mizuno, F. Delage, J. Somers, Metallic fuels for advanced reactors, Journal of Nuclear Materials, 392 (2009) 139-150.

[2] S. Brémier, P. Pöml, K. Inagaki, L. Capriotti, D. Papaioannou, V.V. Rondinella, H. Ohta, T. Ogata, Electron microprobe examination of metallic fuel for minor actinides transmutation in fast reactor, Transactions of the American Nuclear Society, 109 (2013) 616-619.

[3] D. Papaioannou, V.V. Rondinella, H. Ohta, T. Ogata, R. Nasirow, N. Niagolova, Irradiation effects on actinide containing U-Pu-Zr metallic fuels at several burnups, in: ANS Annual Conference, American Nuclear Society, Chicago, IL (June 24-28), 2012.

[4] V.V. Rondinella, H. Ohta, D. Papaioannou, T. Ogata, R. Nasyrow, T. Koyama, J.-P. Glatz, Characterization of metallic fuel for the transmutation of minor actinides in fast reactor, in: ANS Winter Conference, Washington, DC, American Nuclear Society, 2009.

[5] V.V. Rondinella, H. Ohta, D. Papaioannou, T. Ogata, D. Pellottiero, T. Koyama, J.-P. Glatz, Postirradiation examination of metallic fuel for minor actinides transmutation in fast reactor, in: ANS Annual Conference 2010, American Nuclear Society, San Diego, CA (June 13-17), 2010. [6] H. Ohta, T. Ogata, T. Yokoo, M. Ougier, J.-P. Glatz, B. Fontaine, L. Breton, Low-burnup irradiation behavior of fast reactor metal fuels containing minor actinides, Nuclear Technology, 165 (2009) 96-110.

[7] J.M. Harp, H.J.M. Chichester, Preliminary post irradiation examination of AFC-3A and AFC-3B, Transactions of the American Nuclear Society, 110 (2014).

[8] R.D. Mariani, D.L. Porter, S.L. Hayes, J.R. Kennedy, Metallic fuels: the EBR-II legacy and recent advances, Procedia Chemistry, 7 (2012) 513-520.

[9] D.D. Keiser, Jr., J.R. Kennedy, B.A. Hilton, S.L. Hayes, The development of metallic nuclear fuels for transmutation applications: materials challenges, JOM, 60 (2008) 29-32.

[10] C.E. Till, Y.I. Chang, W.H. Hannum, The integral fast reactor--an overview, Progress in Nuclear Energy, 31 (1997) 3-11.

[11] K. Kinoshita, T. Koyama, T. Inoue, M. Ougier, J.-P. Glatz, Separation of actinides from rare earth elements by means of molten salt electrorefining with anodic dissolution of U-Pu-Zr alloy fuel, Journal of Physics and Chemistry of Solids, 66 (2005) 619-624.

[12] D.E. Burkes, R.S. Fielding, D.L. Porter, Metallic fast reactor fuel fabrication for the global nuclear energy partnership, Journal of Nuclear Materials, 392 (2009) 158-163.

[13] C.L. Trybus, J.E. Sanecki, S.P. Henslee, Casting of metallic fuel containing minor actinide additions, Journal of Nuclear Materials, 204 (1993) 50-55.

[14] R.D. Mariani, D.L. Porter, T.P. O’Holleran, S.L. Hayes, J.R. Kennedy, Lanthanides in metallic nuclear fuels: their behavior and methods for their control, Journal of Nuclear Materials, 419 (2011) 263-271.

[15] C. Sari, C.T. Walker, M. Kurata, T. Inoue, Interaction of U-Pu-Zr alloys containing minor actinides and rare earths with stainless steel, Journal of Nuclear Materials, 208 (1994) 201-210. [16] Y.S. Kim, G.L. Hofman, A.M. Yacout, Migration of minor actinides and lanthanides in fast reactor metallic fuel, Journal of Nuclear Materials, 392 (2009) 164-170.

[17] M. Kurata, T. Inoue, C. Sari, Redistribution behavior of various constituents in U-Pu-Zr alloy and $\mathrm{U}-\mathrm{Pu}-\mathrm{Zr}$ alloy containing minor actinides and rare earths in a temperature gradient, Journal of Nuclear Materials, 208 (1994) 144-158. 
[18] T. Inoue, M. Kurata, L. Koch, J.C. Spirlet, C. Sari, Characterization of fuel alloys with minor actinides, in: E.L. Quinn, E.A. Blocher, R.W. Hess, I.O. Macke, E.M. Burke (Eds.) Transactions of the American Nuclear Society, American Nuclear Society, 1991.

[19] D.E. Janney, J.R. Kennedy, J.W. Madden, T.P. O'Holleran, Am phases in the matrix of a U$\mathrm{Pu}-\mathrm{Zr}$ alloy with Np, Am, and rare-earth elements, Journal of Nuclear Materials, 456 (2015) 4653.

[20] D.E. Janney, J.R. Kennedy, As-cast microstructures in U-Pu-Np-Am-Zr alloy fuel pins with 5-8 wt\% minor actinides and 0-1.5 wt\% rare-earth elements, Materials Characterization, 61

(2010) 1194-1202.

[21] K.A. Gschneider, Jr., Cerium-lanthanum binary diagram, in: P. Villars, H. Okamoto, K. Cenzual (Eds.) ASM Alloy Phase Diagram Database, ASM International, Materials Park, OH, 1990.

[22] K.A. Gschneider, Jr., Neodymium-praseodymium binary diagram, in: P. Villars, H.

Okamoto, K. Cenzual (Eds.) ASM Alloy Phase Diagram Database, ASM International, Materials Park, OH, 1990.

[23] K.A. Gschneider, Jr., Lanthanum-neodymium binary diagram, in: P. Villars, H. Okamoto, K. Cenzual (Eds.) ASM Alloy Phase Diagram Database, ASM International, Materials Park, OH, 1990.

[24] K.A. Gschneider, Jr., Cerium-neodymium binary diagram, in: P. Villars, H. Okamoto, K. Cenzual (Eds.) ASM Alloy Phase Diagram Database, ASM International, Materials Park, OH, 1990.

[25] K.A. Gschneider, Jr., Cerium-praseodymium binary diagram, in: P. Villars, H. Okamoto, K. Cenzual (Eds.) ASM Alloy Phase Diagram Database, ASM International, Materials Park, OH, 1990.

[26] K.A. Gschneider, Jr., Lanthanum-praseodymium binary diagram, in: P. Villars, H.

Okamoto, K. Cenzual (Eds.) ASM Alloy Phase Diagram Database, ASM International, Materials Park, OH, 1990.

[27] H. Okamoto, Cerium-plutonium binary diagram, in: P. Villars, H. Okamoto, K. Cenzual (Eds.) ASM Alloy Phase Diagram Database, ASM International, Materials Park, OH, 1990. [28] H. Okamoto, Neodymium-plutonium binary diagram, in: P. Villars, H. Okamoto, K. Cenzual (Eds.) ASM Alloy Phase Diagram Database, ASM International, Materials Park, OH, 1990.

[29] Neodymium, in: Periodic Table of Elements: LANL (http://periodic.lanl.gov/60.shtml) 


\section{Figures}
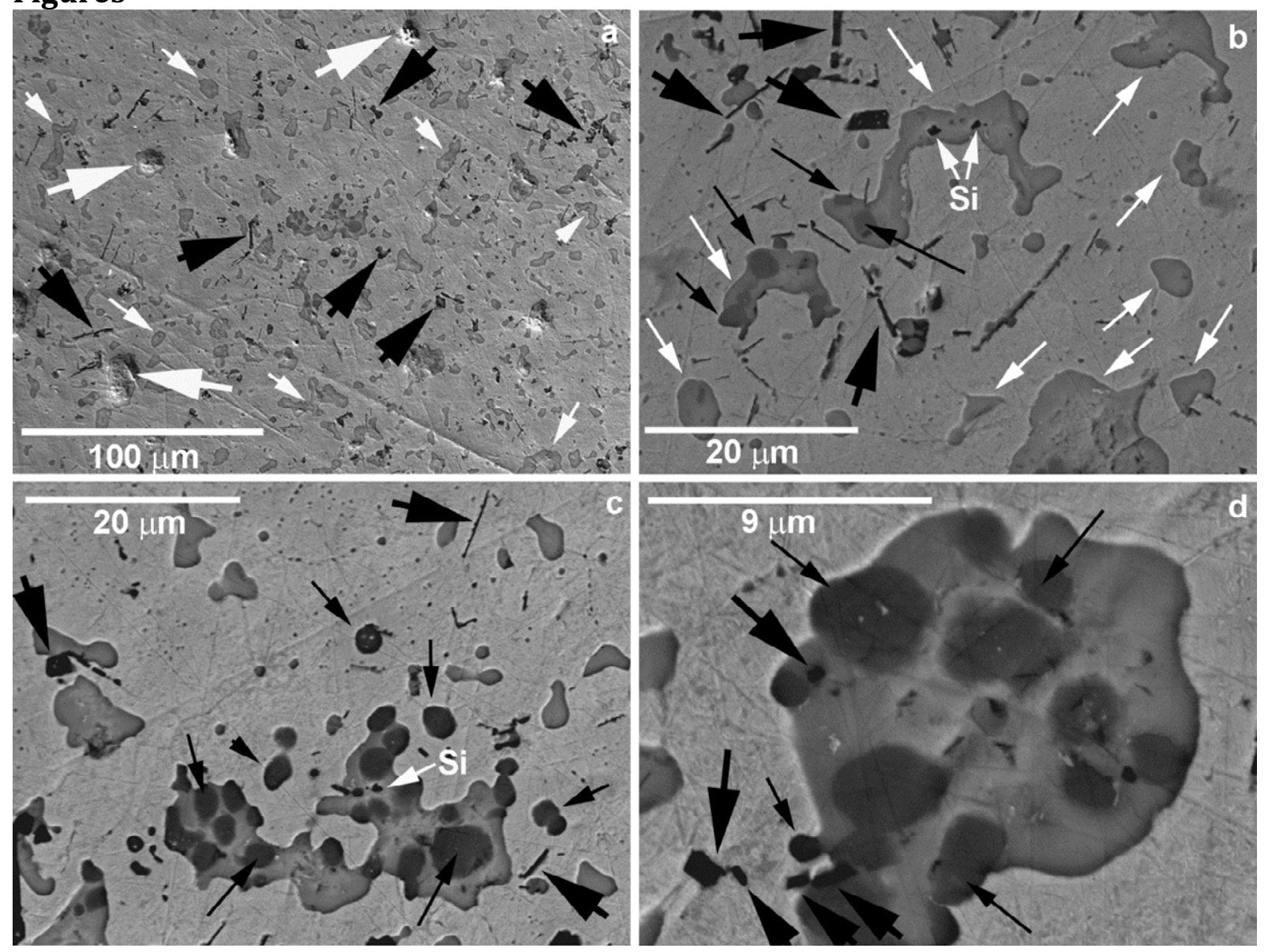

Figure 1: SEM images. Small white arrows: high-Am RE inclusions. Large white arrows:

Surface pitting in large RE inclusions. Small black arrows: Low-Am RE inclusions. Large black arrows: High-Zr inclusions. a) Low-magnification secondary electron (SE) image showing inclusions in a light-contrast matrix. b) Higher-magnification back-scattered electron (BSE) image showing irregularly shaped high-Am RE inclusions, some of which have high-Si or lowAm RE sub-inclusions. c) Higher-magnification BSE view of the area near the center of part a. d) Higher-magnification view of a high-Am RE inclusion with high-Zr and low-Am RE subinclusions. 


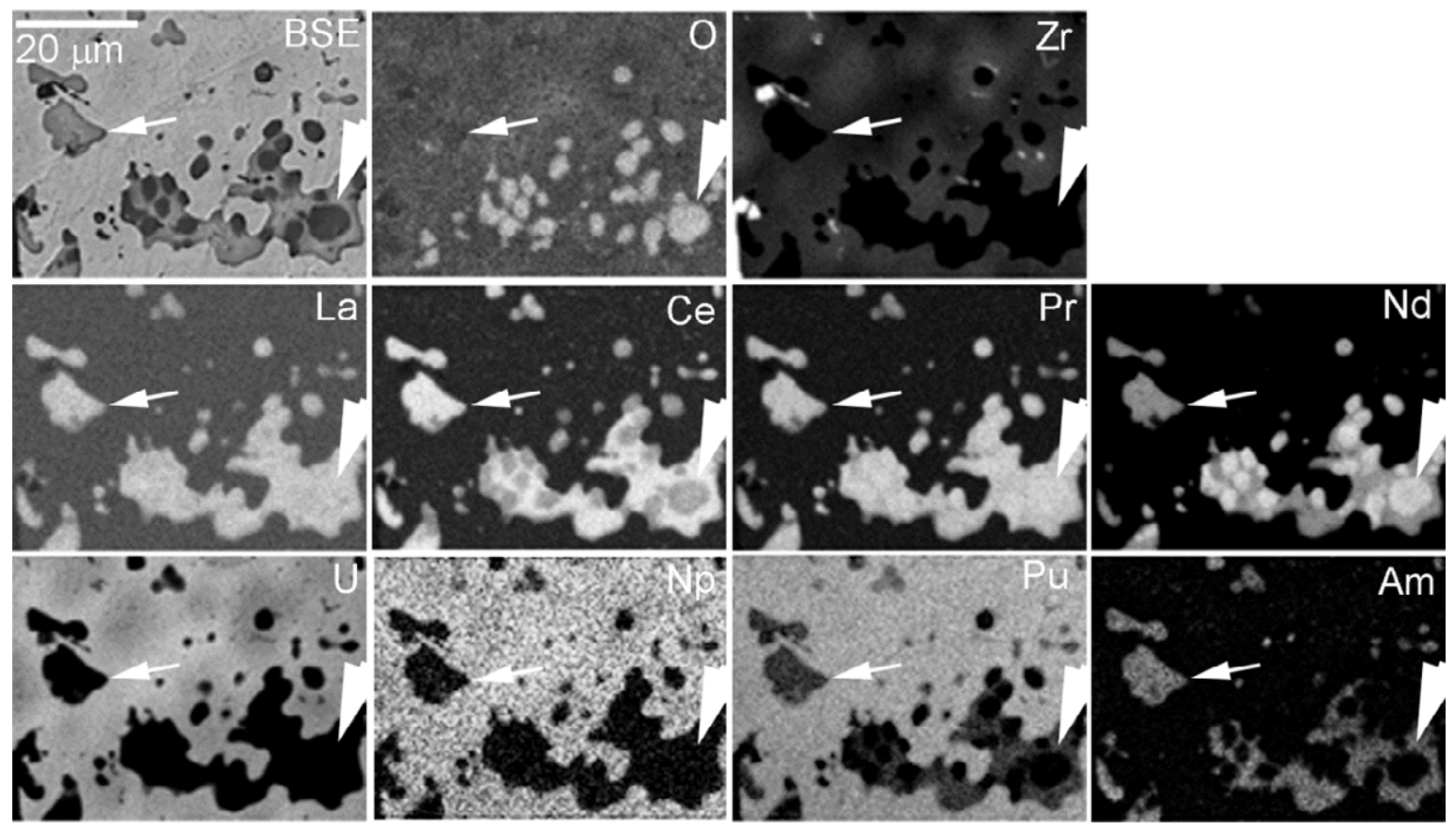

Figure 2: X-ray maps of the area in Figure 1c, showing spatial distributions of elements. Within each map, brighter areas correspond to higher concentrations. Small arrows point to the same high-Am RE inclusion on each map, and large arrows point to the same low-Am inclusion. 


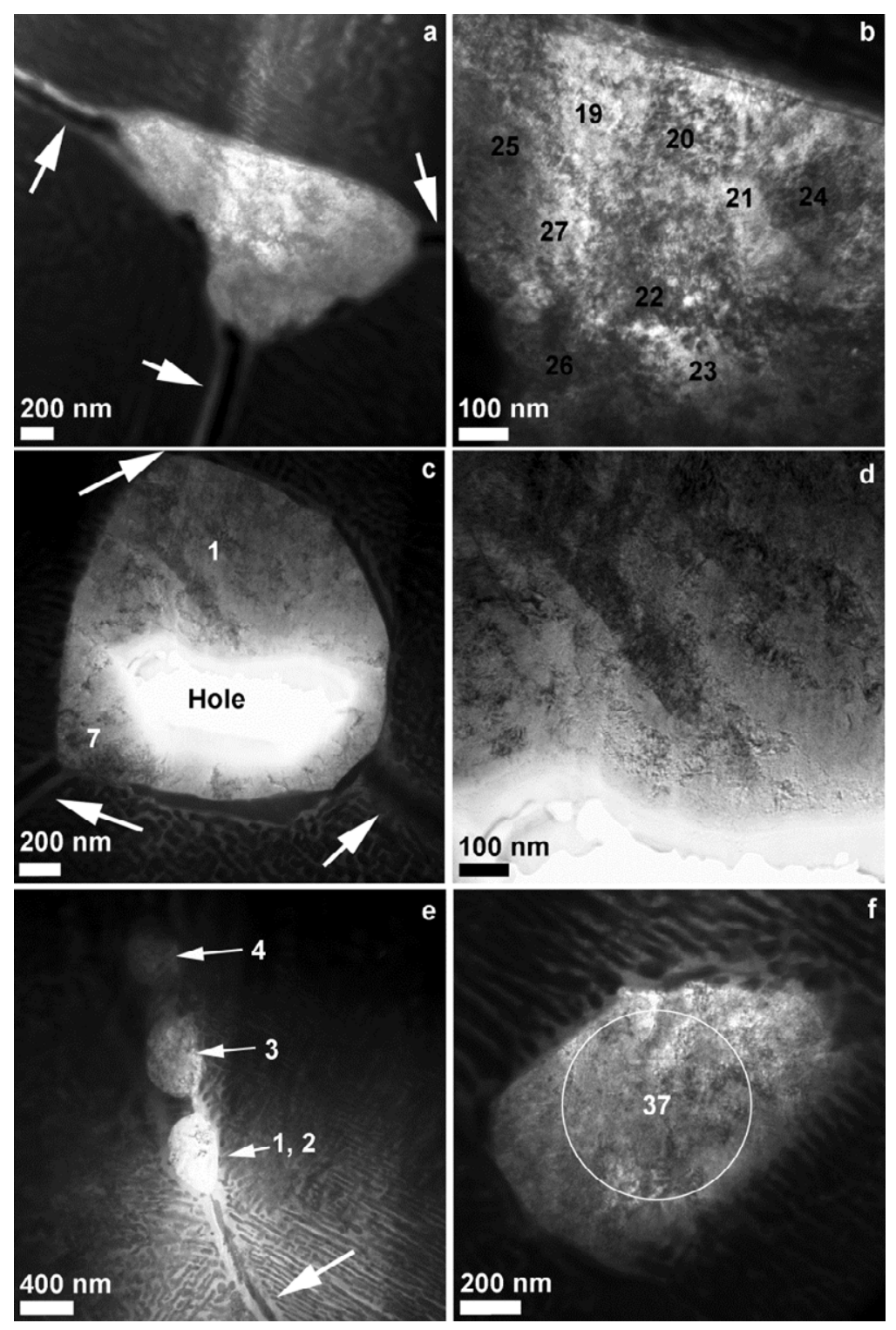

Figure 3: TEM images of high-Am RE inclusions. Numbers show locations of spectra in Table 1. Large white arrows indicate locations of prior grain boundaries from a previous phase [19]. a) Triangular inclusion at intersection of three prior grain boundaries. b) Higher-magnification view of central part of inclusion in part a. c) Rounded inclusion at intersection of three prior grain boundaries. Hole indicates an area where the sample was milled through by the FIB. d) Highermagnification view of area above hole in figure c. e) Three small high-Am RE inclusions along a prior grain boundary. f) Inclusion that does not appear to be on a prior grain boundary. 


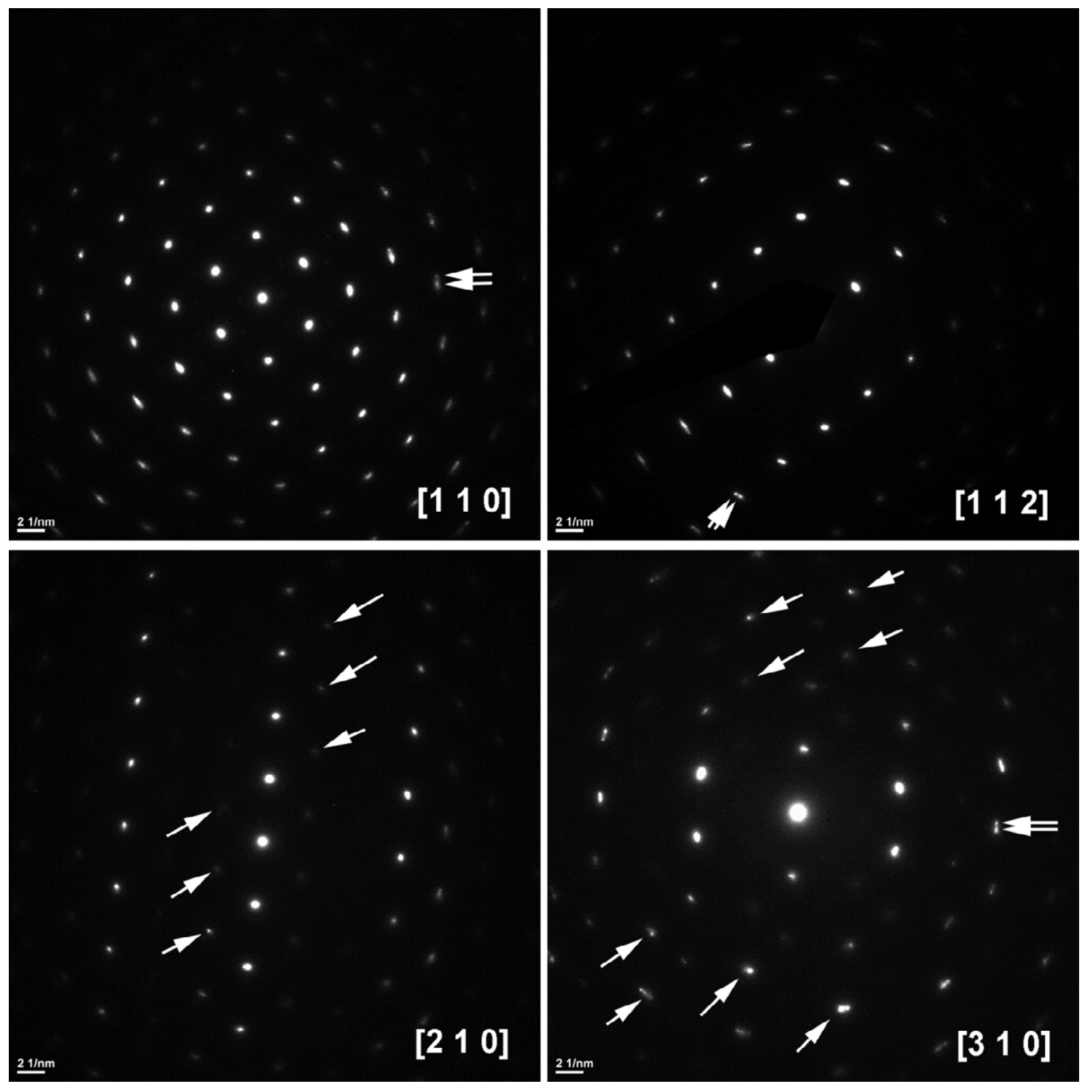

Figure 4: Selected-area electron diffraction patterns from high-Am RE inclusions, indexed using a face-centered cubic structure. Closely spaced pairs of arrows show examples of split reflections. Single arrows show examples of reflections from adjacent crystals. 


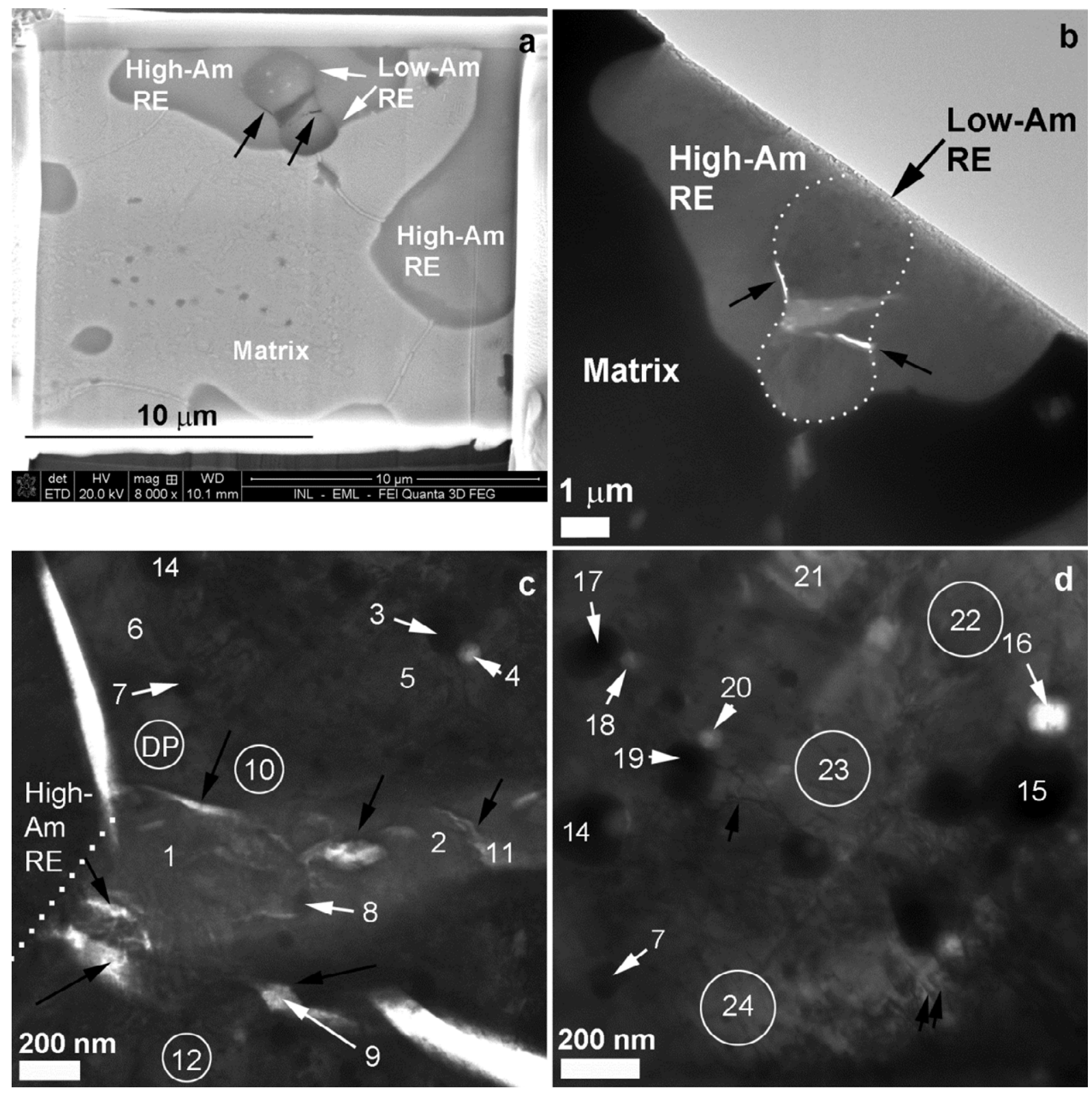

Figure 5: FIB and TEM images of a low-Am RE inclusion. Numbers show locations of EDX spectra in Table 2. a) High-contrast SE image from the FIB during TEM sample preparation. Black arrows show thin, highly elongated areas that can be used to correlate locations in images. b) Low-magnification TEM image of the same low-Am RE inclusion (rotated clockwise relative to part a). Small black arrows indicate the same features as in part a. c) Higher-magnification image showing the left end of the triangular area and adjacent fractures. Black arrows indicate small holes or very thin areas. Elongated white areas extending to upper left and lower right corners of the image are the same as in part b, and are clearly fractures. d) Image overlapping the upper right corner of part c, showing numerous dislocations (e.g., at black arrows) and paired sub-inclusions (e.g., spectra 15 and 16, 17 and 18, and 19 and 20). 


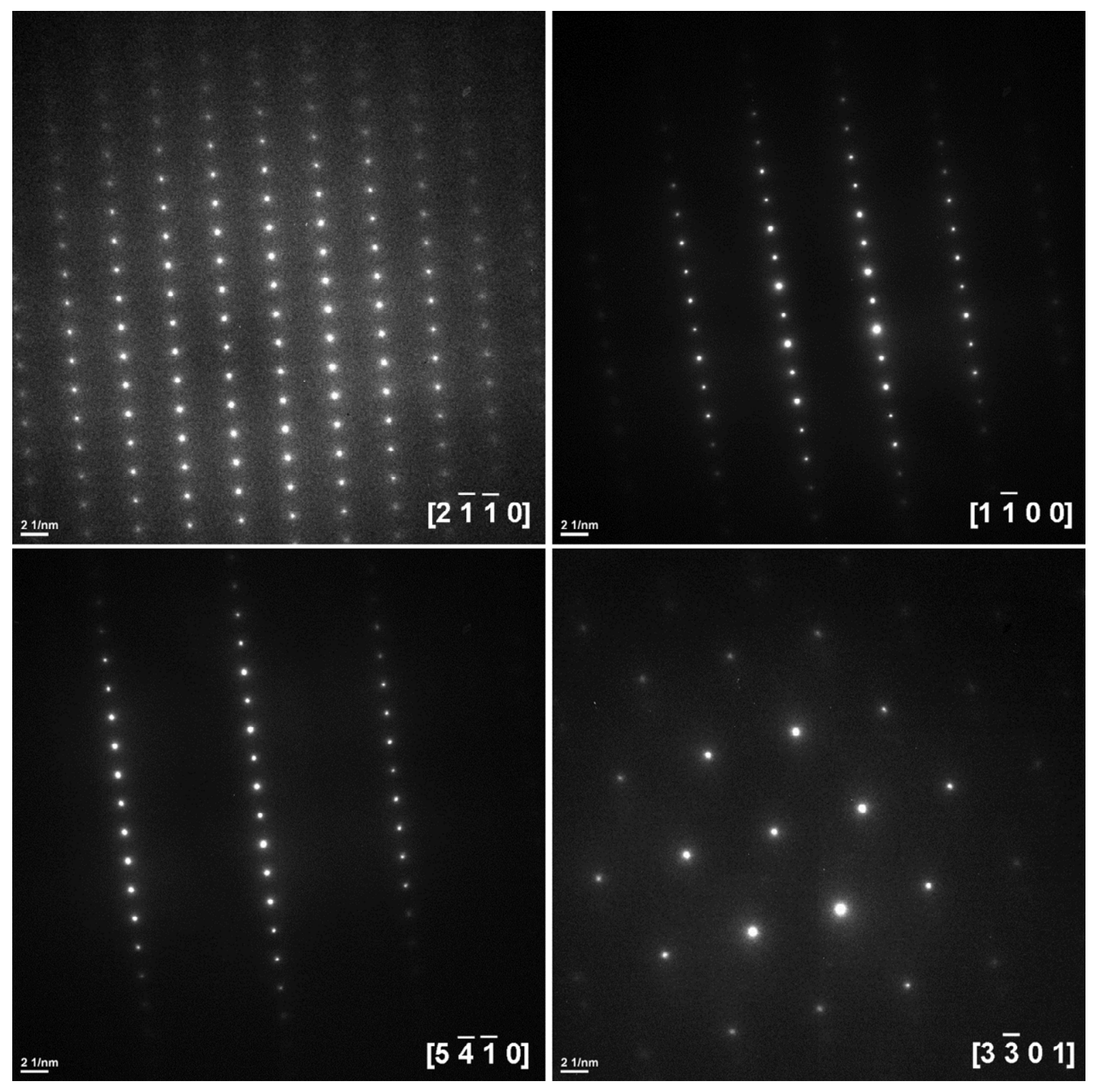

Figure 6: Selected-area electron diffraction patterns from low-Am RE inclusions, indexed using space group $\mathrm{P}-3 \mathrm{~m} 1$ and lattice parameters for $\mathrm{Nd}_{2} \mathrm{O}_{3}$. 
Table 1: EDX spectra from high-Am RE inclusions. Nominal beam diameters are included in names of spectra collected with small beams.

\begin{tabular}{|c|c|c|c|c|c|c|c|c|c|c|c|}
\hline \multirow[b]{2}{*}{ Spectrum } & \multirow{2}{*}{$\begin{array}{r}\text { Image } \\
\text { (Fig. 3) }\end{array}$} & \multicolumn{10}{|c|}{ Element (at\% normalized to $100 \%$ ) } \\
\hline & & $\mathbf{O}$ & $\mathbf{Z r}$ & $\mathbf{L a}$ & Ce & Pr & Nd & $\mathbf{U}$ & $\mathbf{N p}$ & $\mathbf{P u}$ & Am \\
\hline $1 \mathrm{~A} 1-2$ & & 1 & 18 & 4 & 16 & 7 & 39 & 0 & 0 & 4 & 10 \\
\hline $1 \mathrm{~A} 1-3$ & & 7 & 6 & 4 & 18 & 8 & 42 & 0 & 0 & 4 & 10 \\
\hline $1 \mathrm{~A} 2-1$ & $\mathrm{c}, \mathrm{d}$ & 14 & 3 & 3 & 19 & 8 & 37 & 1 & 0 & 4 & 12 \\
\hline $1 \mathrm{~A} 2-7-25 \mathrm{~nm}$ & $\mathrm{c}$ & 20 & 2 & 3 & 19 & 7 & 32 & 1 & 0 & 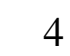 & 12 \\
\hline $1 \mathrm{~A} 3-15-10 \mathrm{~nm}$ & & 4 & 32 & 1 & 12 & 4 & 15 & 13 & 1 & 8 & 11 \\
\hline $1 \mathrm{~A} 4-21-25 \mathrm{~nm}$ & & 1 & 8 & 2 & 20 & 7 & 32 & 2 & 1 & 6 & 22 \\
\hline $1 \mathrm{~A} 4-22-25 \mathrm{~nm}$ & & 3 & 20 & 1 & 15 & 5 & 23 & 10 & 1 & 8 & 15 \\
\hline $1 \mathrm{~A} 4-23-25 \mathrm{~nm}$ & & 0 & 22 & 1 & 13 & 5 & 21 & 14 & 2 & 9 & 14 \\
\hline $1 \mathrm{~A} 5-24$ & & 2 & 34 & 2 & 14 & 6 & 26 & 1 & 0 & 3 & 12 \\
\hline $1 \mathrm{~A} 5-27$ & & 0 & 27 & 2 & 10 & 5 & 20 & 16 & 2 & 9 & 10 \\
\hline $1 \mathrm{~A} 5-30-25 \mathrm{~nm}$ & & 4 & 5 & 4 & 18 & 8 & 39 & 2 & 0 & 5 & 14 \\
\hline $1 \mathrm{~A} 5-32-25 \mathrm{~nm}$ & & 5 & 4 & 2 & 21 & 7 & 35 & 1 & 1 & 6 & 19 \\
\hline 1A6-37 & $\mathrm{f}$ & 9 & 4 & 2 & 20 & 7 & 37 & 1 & 0 & J & 15 \\
\hline $1 C 3-1-25$ & $\mathrm{e}$ & 38 & 2 & 1 & 14 & 5 & 24 & 0 & 0 & 3 & 12 \\
\hline $1 \mathrm{C} 3-2$ & $\mathrm{e}$ & 39 & 2 & 1 & 14 & 5 & 23 & 0 & 0 & 3 & 12 \\
\hline $1 C 3-3$ & e & 15 & 4 & 2 & 20 & 7 & 30 & 1 & 0 & 4 & 17 \\
\hline $1 C 3-4$ & e & 0 & 21 & 2 & 17 & 6 & 23 & 7 & 1 & 7 & 17 \\
\hline $1 \mathrm{C} 5-13$ & & 3 & 6 & 2 & 20 & 8 & 36 & 2 & 1 & 5 & 16 \\
\hline $1 \mathrm{C} 5-1$ & & 8 & 5 & 2 & 20 & 7 & 34 & 2 & 0 & 5 & 16 \\
\hline 1C6-1 & $a, b$ & 6 & 4 & 4 & 19 & 8 & 40 & 2 & 0 & 4 & 13 \\
\hline $1 \mathrm{C} 6-2$ & $a, b$ & 5 & 4 & 4 & 20 & 8 & 40 & 1 & 1 & 4 & 13 \\
\hline $5 \mathrm{~nm}$ & $a, b$ & 3 & 3 & 5 & 20 & 9 & 43 & 1 & 0 & 5 & 11 \\
\hline $5 \mathrm{~nm}$ & $a, b$ & 0 & 4 & 4 & 20 & 9 & 42 & 1 & 1 & 5 & 12 \\
\hline $1 \mathrm{C} 6-23-15 \mathrm{~nm}$ & $a, b$ & 1 & 3 & 5 & 21 & 9 & 45 & 1 & 0 & 5 & 11 \\
\hline $15 \mathrm{~nm}$ & $a, b$ & 10 & 3 & 4 & 19 & 8 & 39 & 1 & 0 & 4 & 11 \\
\hline $1 \mathrm{C} 6-25-15 \mathrm{~nm}$ & $a, b$ & 2 & 4 & 5 & 20 & 9 & 42 & 1 & 0 & 5 & 12 \\
\hline $1 \mathrm{C} 6-26-15 \mathrm{~nm}$ & $a, b$ & 5 & 4 & 5 & 19 & 8 & 40 & 1 & 0 & 5 & 12 \\
\hline $1 \mathrm{C} 6-27-15 \mathrm{~nm}$ & $a, b$ & 7 & 3 & 4 & 19 & 9 & 40 & 1 & 1 & 4 & 12 \\
\hline $1 C 7-30$ & & 2 & 20 & 0 & 9 & 5 & 19 & 9 & 1 & 9 & 25 \\
\hline $1 \mathrm{C} 7-32-25 \mathrm{~nm}$ & & 1 & 11 & 2 & 16 & 7 & 27 & 5 & 1 & 8 & 23 \\
\hline $1 C 7-33-25 \mathrm{~nm}$ & & 0 & 18 & 0 & 12 & 4 & 22 & 7 & 1 & 9 & 27 \\
\hline 2A1-DP2 & $-{ }^{1}$ & 10 & 2 & 5 & 18 & 9 & 43 & 0 & 0 & 4 & 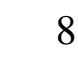 \\
\hline 2A1-14 & $-{ }^{1}$ & 0 & 3 & 5 & 19 & 10 & 48 & 1 & 0 & 5 & 9 \\
\hline
\end{tabular}

${ }^{1}$ Adjacent to low-Am RE inclusion in Figure 5 
Table 2: EDX spectra from the low-Am RE inclusion. Nominal beam diameters are included in names of spectra collected with small beams. Spectra in bold type and italics are from dark and light sub-inclusions, respectively. Other spectra are from areas outside sub-inclusions. Locations of spectra are shown in Figures $5 \mathrm{c}$ and $5 \mathrm{~d}$.

\begin{tabular}{|c|c|c|c|c|c|c|c|c|c|c|}
\hline \multirow[b]{2}{*}{ Spectrum } & \multicolumn{10}{|c|}{ Element (at\% normalized to $100 \%$ ) } \\
\hline & $\mathbf{O}$ & $\mathbf{Z r}$ & $\mathbf{L a}$ & $\mathrm{Ce}$ & Pr & Nd & $\mathbf{U}$ & Np & $\mathbf{P u}$ & A \\
\hline A1-1-25 nm & 51 & & 2 & 7 & & 34 & 0 & 0 & 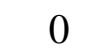 & \\
\hline $5 \mathrm{~nm}$ & 52 & & 2 & 7 & & 33 & 0 & & & \\
\hline nm & 20 & 19 & 4 & 8 & 3 & 34 & 4 & 1 & & \\
\hline 7 & 34 & 1 & 6 & 10 & 6 & 42 & & & & \\
\hline 11 & 37 & & 5 & 10 & & 1 & & & & \\
\hline $\mathrm{n}$ & 35 & 1 & 3 & 9 & 6 & 4 & & & & \\
\hline & 34 & 2 & 4 & 11 & 6 & 41 & $\mathbf{0}$ & $\mathbf{0}$ & & \\
\hline & 54 & 6 & 2 & 5 & 4 & 26 & 2 & 0 & & \\
\hline & 45 & 1 & . & 9 & 5 & 35 & & & & \\
\hline & 3 & & 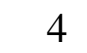 & & & 43 & & & & \\
\hline $\mathrm{n}$ & 44 & 1 & 2 & 8 & & 40 & 0 & 0 & & \\
\hline A 1 & 34 & 2 & 4 & 9 & 7 & 42 & 0 & & & \\
\hline & 29 & 9 & 5 & 10 & 6 & 34 & 2 & 0 & & \\
\hline & 12 & 27 & 4 & 9 & & 5 & 8 & 1 & & \\
\hline & 41 & 1 & 5 & 8 & 6 & 39 & 0 & 0 & & \\
\hline n & 32 & 12 & 4 & & 5 & 33 & 3 & 0 & & \\
\hline$m$ & 39 & 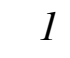 & 5 & s & 6 & 39 & 0 & 0 & & \\
\hline & 29 & 13 & 4 & & & 33 & 3 & & & \\
\hline & 35 & ? & 5 & 10 & J & 41 & 0 & & & \\
\hline & 39 & 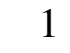 & 4 & 9 & 6 & 40 & 0 & 0 & & \\
\hline & 35 & 3 & 5 & 9 & 7 & 41 & 0 & 0 & & \\
\hline & 34 & 1 & 5 & 10 & 1 & 42 & 0 & 0 & 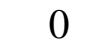 & \\
\hline 2 & 34 & & 5 & 10 & 7 & 42 & 0 & 0 & 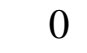 & \\
\hline
\end{tabular}

